\title{
CFD Analysis for Heat Transfer Enhancement inside a Circular Tube with Half-Length Upstream and Half-Length Downstream Twisted Tape
}

\author{
R. J. Yadav ${ }^{1}$ and A. S. Padalkar² \\ ${ }^{1}$ Department of Mechanical Engineering, MIT College of Engineering, Pune-411028, India \\ ${ }^{2}$ Department of Mechanical Engineering, Flora Institute of Technology, Pune-412205, India \\ Correspondence should be addressed to R. J. Yadav, rupesh_yadava@rediffmail.com
}

Received 30 August 2012; Revised 31 October 2012; Accepted 31 October 2012

Academic Editor: Ahmet Z. Sahin

Copyright ( 2012 R. J. Yadav and A. S. Padalkar. This is an open access article distributed under the Creative Commons Attribution License, which permits unrestricted use, distribution, and reproduction in any medium, provided the original work is properly cited.

CFD investigation was carried out to study the heat transfer enhancement characteristics of air flow inside a circular tube with a partially decaying and partly swirl flow. Four combinations of tube with twisted-tape inserts, the half-length upstream twisted-tape condition (HLUTT), the half-length downstream twisted-tape condition (HLDTT), the full-length twisted tape (FLTT), and the plain tube (PT) with three different twist parameters $(\lambda=0.14,0.27$, and 0.38$)$ have been investigated. 3D numerical simulation was performed for an analysis of heat transfer enhancement and fluid flow for turbulent regime. The results of CFD investigations of heat transfer and friction characteristics are presented for the FLTT, HLUTT, and the HLDTT in comparison with the PT case.

\section{Introduction}

The heat transfer enhancement technology (HTET) has been developed and widely applied to heat exchanger applications over last decade, such as refrigeration, automotives, process industry, nuclear reactors, and solar water heaters. Till date, there have been many attempts to reduce the sizes and the costs of the heat exchangers and their energy consumption with the most influential factors being heat transfer coefficients and pressure drops, which generally lead to the incurring of less capital costs.

HTET can offer significant economic benefits in various industrial processes. By "augmentation" we mean an enhancement in heat transfer, over that which is existent on the reference surface for similar operating conditions.

Bergles and Webb $[1,2]$ have reported comprehensive reviews on techniques for heat transfer enhancement. For a single-phase heat transfer, the enhancement has been brought using roughened surfaces and other augmentation techniques, such as swirl/vortex flow devices and modifications to duct cross sections and surfaces. These are the passive augmentation techniques, which can increase the convective heat transfer coefficient on the tube side. Many techniques for the enhancement of heat transfer in tubes have been proposed over the years.

Siddique et al. [3] reported the following heat transfer enhancers in his review paper: (a) extended surfaces including fins and microfins, (b) porous media, (c) large particles suspensions, (d) nanofluids, (e) phase-change devices, (f) flexible seals, (g) flexible complex seals, (h) vortex generators, (i) protrusions, and (j) ultrahigh thermal conductivity composite materials. Many methods that assist in heat transfer enhancement effects have been extracted from the literature.

Among of these methods discussed in the literature are using joint fins, fin roots, fin networks, biconvections, permeable fins, porous fins, and helical microfins and using complicated designs of twisted-tapes. The authors concluded that more attention should be made towards single phase heat transfer augmented with microfins in order to alleviate the disagreements between the works of the different authors.

Also, it was noted that additional attention should be made towards uncovering the main mechanisms of heat 
TABLE 1: The highest recorded heat transfer enhancement level estimated due to each enhancer, (Siddique et al. [3]).

\begin{tabular}{lc}
\hline Heat transfer enhancer type & (Heat transfer due presence of the enhancer/heat transfer in absence of the enhancer) \\
\hline Fins inside tubes & $2.0,[4]$ \\
Microfins inside tubes & 4.0 for laminar, [5] \\
Porous media & $\approx 12.0$ (keff/kf), [6] \\
Nanofluids & $3.5,[7]$ \\
Flexible seals & $2.0,[8]$ \\
Flexible complex seals & $3.0,[9]$ \\
Vortex generators & $2.5,[10]$ \\
Protrusions & $2.0,[11,12]$ \\
Ultra high thermal conductivity composite materials & $6,[13]$ \\
\hline
\end{tabular}

transfer enhancements due to the presence of nanofluids. Further, it can be concluded that perhaps the successful modeling of flow and heat transfer inside porous media as seen in the works of Kim and Kuznetsov [14], which is a wellrecognized passive enhancement method, could help in well discovering the mechanism of heat transfer enhancements due to nanofluids. This is due to some similarities between both media. Additionally, many recent works related to passive augmentations of heat transfer using vortex generators, protrusions, and ultra high thermal conductivity composite material have been reported by the authors. Whereas, Nield and Kuznetsov [15] reported an analysis of laminar forced convection in a helical pipe of circular cross section and filled by a porous medium saturated with a fluid, for the case when the curvature and torsion of the pipe are both small. Later Cheng and Kuznetsov [16, 17] carried out an investigation of laminar flow in a helical pipe filled with a fluid saturated porous medium. The maximum levels of the heat transfer enhancement estimated due to each enhancer were presented in Table 1.

Inside the round tubes, a wide range of inserts, such as tapered spiral inserts, wire coil, twisted-tape with different geometries, rings, disks, streamlined shapes, mesh inserts, spiral brush inserts, conical-nozzles, and V-nozzles, have been used Promvonge and Eiamsa-ard [18] and Promvonge [19].

Smithberg and Landis [20] have estimated the tape-fin effect assuming a uniform heat transfer coefficient on the tape wall, equal to that on the tube wall. Authors reported that the fin effect increases the heat transfer but in practice, the tape-fin effect will not attain such a high value due to the poor contact between the tape and the tube. In order to estimate the tape fin effect, Lopina and Bergles [21] conducted experiments using insulated tapes. Assuming zero contact resistance between tube and tape with equal and uniform heat transfer coefficients on tube and tape walls authors predicted from $8 \%$ to $17 \%$ of the heat is transferred through the tape.

Date [22] reported the prediction of fully developed, laminar and turbulent, and uniform-property flow in a tube containing a twisted-tape. The predictions have shown that significant augmentation in heat transfer can be obtained at high Reynolds and Prandtl numbers, low twist ratios, and high fin parameters.
Manglik and Bergles [23] presented experimental correlations for pressure drop and heat transfer coefficient for laminar, transition, and turbulent flow in isothennal-wall tubes with twisted-tape inserts. Unlike previous correlations, they included the tape thickness in order to properly account for the helical twisting of the streamlines.

Al-Fahed et al. [24] reported an experimental work to study the heat transfer and friction characteristics in a microfin tube fitted with twisted-tape inserts for three different twist/width ratios under laminar flow region.

Saha and Dutta [25] reported investigation on the experimental data on swirl flow due to twisted-tape in laminar region for friction factor and Nusselt number for a large Prandtl number range (from 205 to 518). The author observed that, on the basis of a constant pumping power, short-length twisted-tape is a good choice because in this case swirl generated by the twisted-tape decays slowly downstream which increases the heat transfer coefficient with minimum pressure drop, as compared with a full-length twisted-tape.

Whereas, the concluding remarks from earlier studies on numerical and experimental work are as follows.

Rahimi et al. [26] carried out experimental and CFD studies on heat transfer and friction factor characteristics of a tube equipped with modified twisted-tape inserts. The investigations are with the classic and three modified twisted-tape inserts. The authors observed that the Nusselt number and performance of the jagged insert were higher than other ones.

Eiamsa-ard et al. [27] carried out the numerical analysis of heat and fluid flows through a round tube fitted with twisted-tape. The author investigated the effect of tape clearance ratio on the flow, heat transfer, and friction factor.

Chiu and Jang [28] studied numerically and experimentally three-dimensional gas-fluid flow and heat transfer inside tubes with longitudinal strip inserts (both with/without holes) and twisted-tape inserts twisted at three different angles $\left(\alpha=34.3^{\circ}, 24.4^{\circ}\right.$, and $\left.15.3^{\circ}\right)$.

From above studies it could be concluded that the tube-tape inserts in a full length of tube provide one of the most attractive heat transfer augmentative techniques for flow inside the tube on account of its simplicity and the effectiveness. The short-length twisted-tape $s$ have been considered by many researchers due to reduction of pressure drop while augmenting the heat transfer simultaneously. 


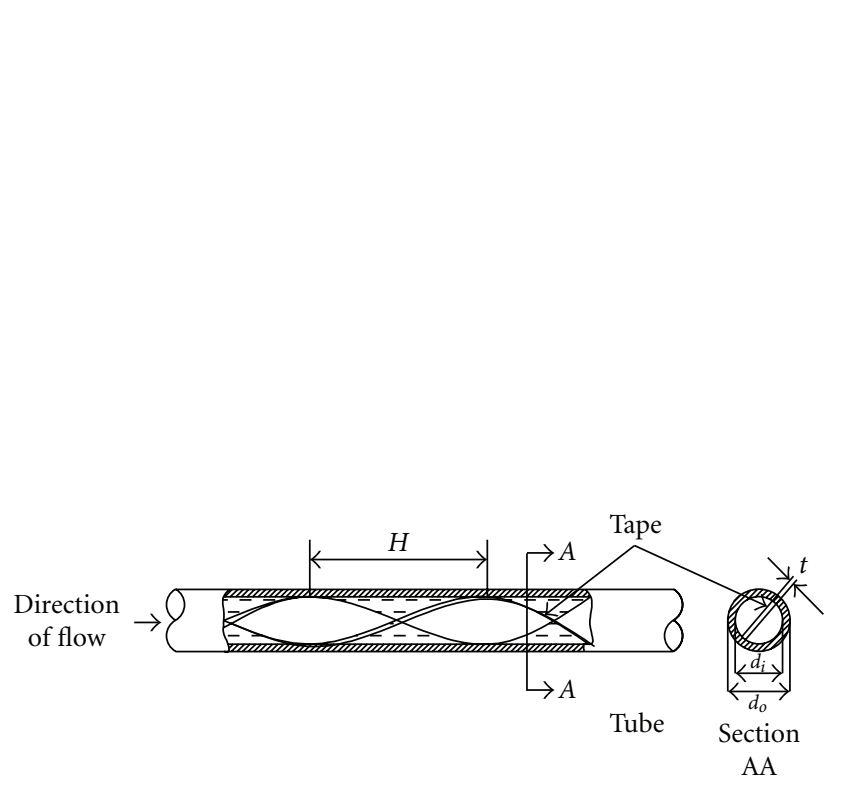

(a)
Different locations of twisted-tape configurations under study
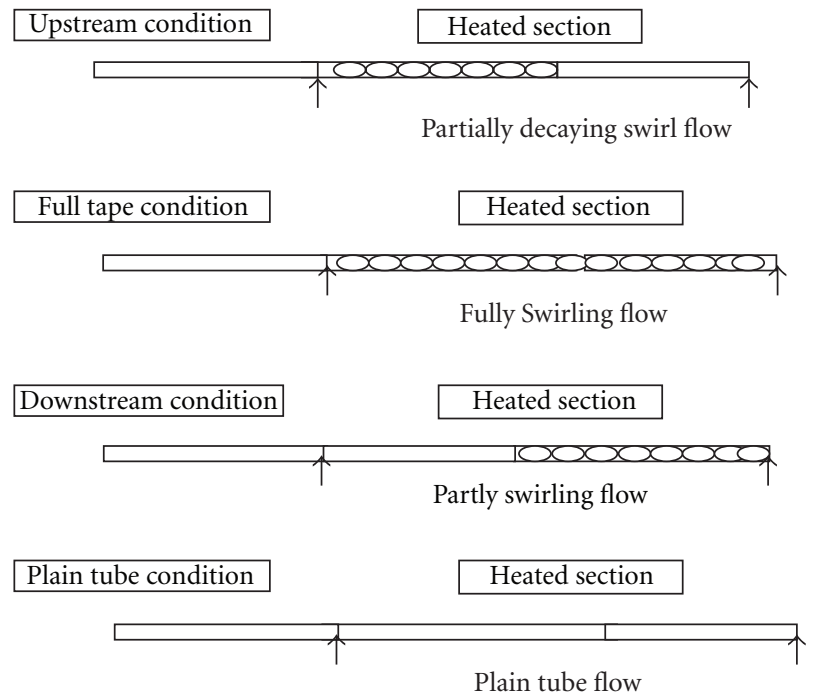

(b)

Figure 1: Problem definition geometrical configuration (a), physical model of the problem defined (b). Different configurations under study.

A CFD prediction of the heat transfer and friction characteristics of the partially decaying swirl flows in the turbulent flow regime has been taken up to study the structure of velocity and temperature fields. The effects of the twisted-tape location on pressure drop and heat transfer characteristics due to creation of swirl in the turbulent flow within the tubes were also studied.

\section{Numerical Simulations}

2.1. Physical Model. The numerical simulations were carried out using the CFD software package FLUENT-6.2.16 that uses the finite-volume method to solve the governing equations.

Geometry was created for air flowing in an electrically heated stainless steel tube of $22 \mathrm{~mm}$ diameter $(D)$ and length (L) 90 times the diameter as in the experimental setup as shown in Figure 1. A computational model has been created in GAMBIT-2.2.30 as shown in Figure 3.

In this study, the effects of the twist parameter $(\lambda=$ $d / H=0.14,0.27$, and 0.38 ) and the two heat flux inputs $\left(Q=2300\right.$ and $\left.6200 \mathrm{~W} / \mathrm{m}^{2}\right)$ on heat transfer rate $(\mathrm{Nu})$, friction factor $(f)$, and thermal performance factor $(\eta)$ are examined under uniform heat flux conditions with air as the testing fluid and with different inlet frontal velocities with Reynolds number, Re between 25000 and 110000 .

Twisted-tape inserts under the following locations of the twisted-tape configurations were used.

(a) Upstream condition (HLUTT) - tube with twistedtapes located in the first half of 50 diameters of the heated section. (Partially decaying swirl flow.)

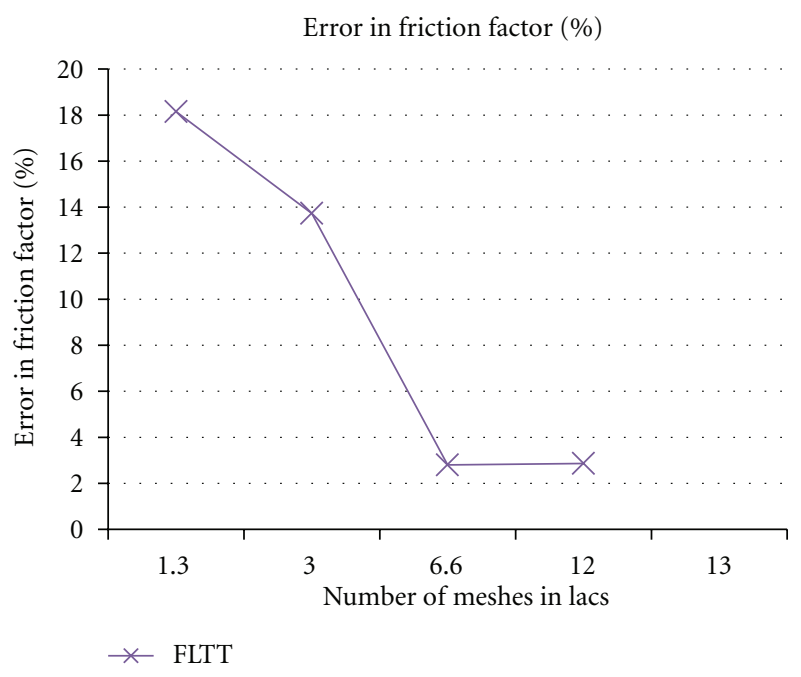

Figure 2: Grid independence test.

(b) Downstream condition (HLDTT) - tube with twisted-tapes located in the second half of 50 diameters of the heated section. (Partly swirl flow.)

(c) Full-length condition (FLTT)-tube with twistedtapes located in the full length of the heated section. (Fully swirl flow.)

(d) Plain tube condition (PT) - tube without twistedtapes in the full length of the heated section. (Smooth tube flow.)

2.2. Numerical Method. The available finite-difference procedures for swirling flows and boundary layer are employed 


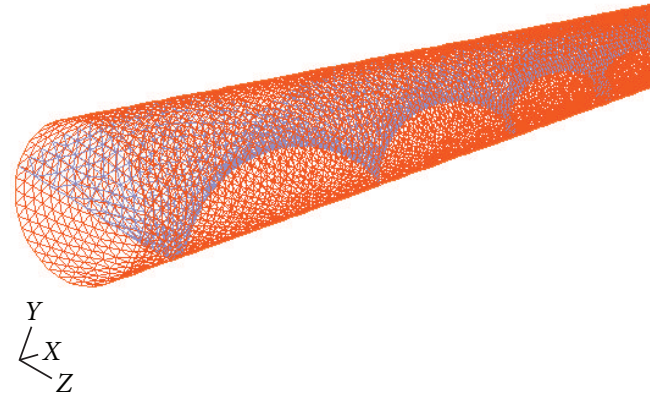

$\begin{array}{lr}\text { Grid } & \text { Apr 18, 2012 } \\ \text { FLUENT 6.3 (3d, dp, pbns, and sstkw) }\end{array}$

Figure 3: Partial view of tube with twisted-tape inside.

to solve the governing partial differential equations. Some simplifying assumptions are required for applying of the conventional flow equations and energy equations to model the heat transfer process in tube with twisted-tape.

For turbulent, steady, and incompressible air flow with constant properties, while we neglect the natural convection and radiation, we follow the three-dimensional equations of continuity, momentum, and energy, in the fluid region. These equations are as below.

Continuity equation:

$$
\frac{\partial \rho}{\partial t}+\nabla \cdot(\overline{\rho v})=0
$$

Momentum equation:

$$
\frac{\partial(\overline{\rho v})}{\partial t}+\nabla \cdot(\overline{\rho v v})=-\nabla p+\nabla \cdot(\bar{\tau})+\rho \bar{g} .
$$

Energy equation:

$$
\frac{\partial(\rho E)}{\partial t}+\nabla \cdot(v(\rho E+p))=\nabla \cdot\left(k_{\mathrm{eff}} \nabla T+\left(\overline{\tau_{\mathrm{eff}}} \cdot \bar{v}\right)\right) .
$$

In the Reynolds-averaged approach for turbulence modeling, the Reynolds stresses in (2) are appropriately modeled by a method that employs the Boussinesq hypothesis to relate the Reynolds stresses to the mean velocity gradients as shown below:

$$
-\rho \overline{u i^{\prime} u j^{\prime}}=\mu_{t}\left(\frac{\partial u i}{\partial x j}+\frac{\partial u j}{\partial x i}\right)-\frac{2}{3}\left(\rho \kappa+\mu_{t} \frac{\partial u \kappa}{\partial x \kappa}\right) \delta i j .
$$

An appropriate turbulence model is used to compute the turbulent viscosity term $\mu_{t}$. The turbulent viscosity is given as

$$
\mu_{t}=\rho C \mu \frac{k^{2}}{\varepsilon}
$$

The second-order upwind scheme was used to discretize the convective term. The linkage between the velocity and pressure was computed using the SIMPLE algorithm. The standard wall treatment model was chosen for the near-wall modeling method.
For validating the accuracy of numerical solutions, the grid independent test has been performed for the physical model. The grid is highly concentrated near the wall and in the vicinity of the twisted-tape. Four grid systems with about $130000,300000,660000$, and 1200000 cells are adopted to calculate grid independence. We compared the friction factors for these four mesh configurations as shown in Figure 2. After checking the grid independence test, the simulation grid in this study was meshed using about 6, 60,000 cells that consisted of tetrahedral grid.

Figure 3 shows an example of the partial-meshed configuration of the round tube equipped with a twisted-tape. It consists of a tube of diameter $22 \mathrm{~mm}$ containing twistedtape insert, test section $2000 \mathrm{~mm}$, and calming section of $1200 \mathrm{~mm}$ dimensions just like those in experimental setup with twist angle 0.14 . To capture wall gradient effects, mesh has been finer toward the walls. There are a total of $6,60,000$ nodes in the domain simulation.

In addition, a convergence criterion of $10^{-6}$ was used for energy and $10^{-3}$ for the mass conservation of the calculated parameters.

The air inlet temperature was specified as $300 \mathrm{~K}$, and three assumptions were made in the model: (1) the uniform heat flux was along the length of test section, (2) the wall of the inlet calming section was adiabatic, and (3) the physical properties of air were constant and were evaluated at the bulk mean temperature. The velocity inlet boundary condition was adopted at the inlet and outflow at the outlet of the domain shown in Figure 1.

2.3. Data Reduction. In order to express the experimental results in a more efficient way, the measured data was reduced using the following procedure. Three important parameters considered were the friction factor, the Nusselt number, and the thermal performance factor, which were used for determining the friction loss, heat transfer rate, and the effectiveness of heat transfer enhancement in the tube, respectively. The friction factor $(f)$ is computed from pressure drop, $\Delta P$ across the length of the tube $(L)$ using the following equation:

$$
f=\frac{\Delta P}{(L / D) \cdot\left(\rho U^{2} / 2\right)} .
$$

The Nusselt number is defined as

$$
\mathrm{Nu}=\frac{h \cdot D}{k} .
$$

The average Nusselt number can be obtained by

$$
\mathrm{Nu}_{\mathrm{avg}}=\int \mathrm{Nu}(x) \frac{\partial x}{L} .
$$

The various characteristics of the flow, the Nusselt number, and the Reynolds number were based on the average of the tube wall and the outlet air temperatures. The local wall temperature, inlet and outlet air temperatures, the pressure drop across the test section, and the air flow velocity were measured for heat transfer of the heated tube with 


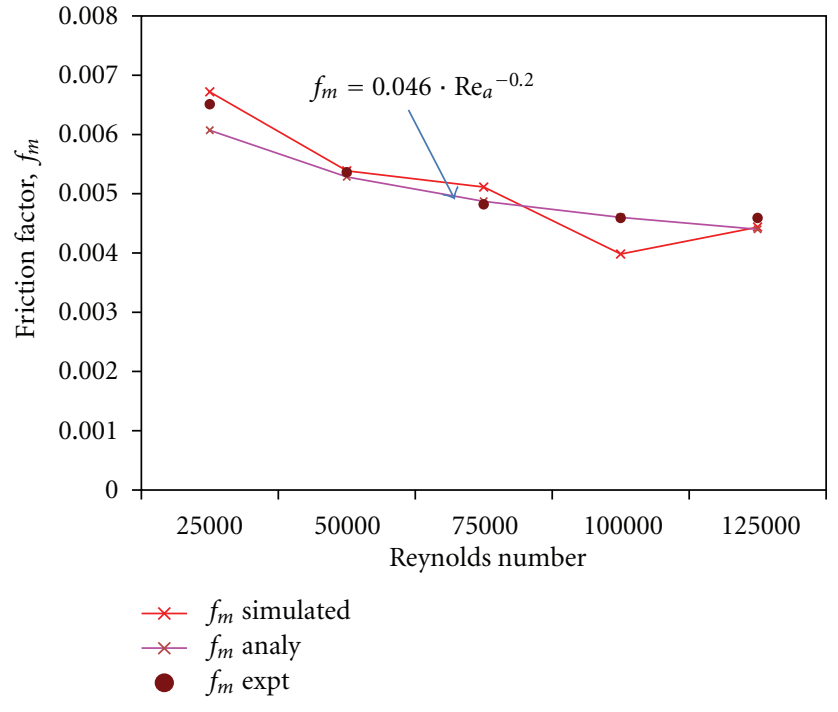

(a) Friction factor verses Reynolds number

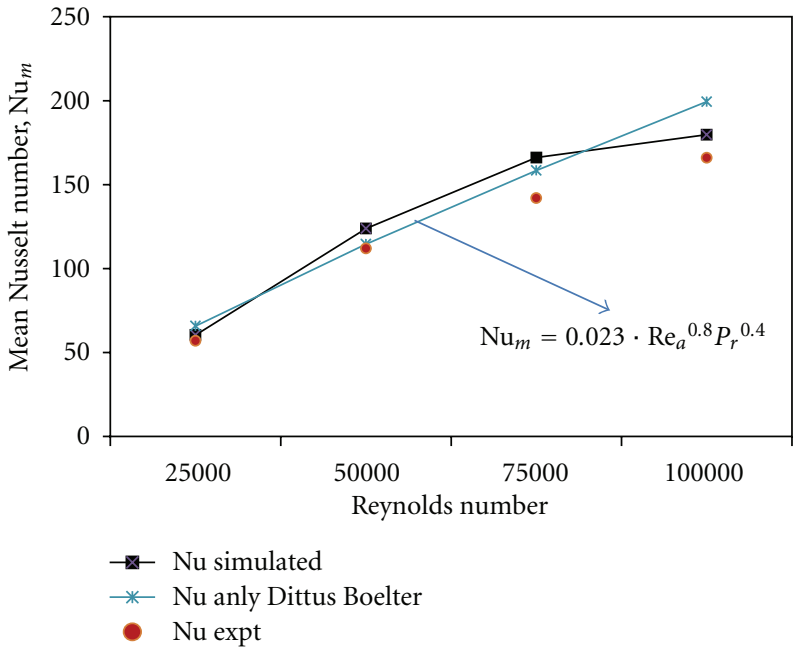

(b) Nu verses Reynolds number

Figure 4: Comparison of CFD results with experimental data and correlations.

different tube inserts. The average Nusselt numbers and friction factors were calculated, and all fluid properties were determined at the overall bulk mean temperature.

Thermal performance factor was given by

$$
\eta=\frac{\mathrm{Nu} / \mathrm{Nu}_{\mathrm{o}}}{\left(f / f_{\mathrm{o}}\right)^{1 / 3}}
$$

where in $\mathrm{Nu}_{\mathrm{o}}, \mathrm{Nu}, f_{\mathrm{o}}$, and $f$ were the Nusselt numbers and friction factors for the plain tube and the tube with twistedtape swirl generator, respectively.

\section{Results and Discussion}

3.1. Validation of Setup. The CFD simulation result of the plain tube (PT) without a twisted-tape insert has been validated with the experimental data as shown in Figures 4(a) and 4(b). The Dittus-Boelter equation for the heat transfer and the Blasius equation for the friction factor are the correlations used for the comparison. These results are within $\pm 15 \%$ deviation for the heat transfer $(\mathrm{Nu})$ and $\pm 6 \%$ for the friction factor $(f)$. Similarly, the CFD results for the plain tube are compared with analytical correlations. The CFD results are within $\pm 9 \%$ deviation for the heat transfer $(\mathrm{Nu})$ and $\pm 6 \%$ for the friction factor $(f)$ with slightly higher deviation of $\pm 17 \%$ for Re higher than 75000 .

3.2. Heat Transfer. Effect of the FLTT twisted-tapes and HLUTT twisted-tapes on the heat transfer rate is presented in Figure 5. The results for the tube fitted with HLUTT and HLDTT have been compared with those for a plain tube and the FLTT under similar operating conditions for $\lambda=0.14$.

It was seen that the effect of different inserts on the heat transfer rate was significant for all the Reynolds numbers used due to the induction of high reverse flows and disruption of boundary layers. This technique has resulted in an improvement of the heat transfer rate over the plain tube.

It is clearly seen that as the Reynolds number goes on increasing, the heat transfer coefficient also goes on increasing.

It was found that the heat transfer coefficients in the tubes with the FLTT were $29-86 \%$ greater than those in the case of the plain tubes without inserts.

When the twisted-tape inserts with the HLUTT condition were used, the heat transfer coefficients were 8-37\% higher than those of the plain tubes. However, the twistedtape inserts with the HLUTT and HLDTT conditions had $15-95 \%$ reduction in values for the heat transfer coefficient when compared to the FLTT condition. Whereas when the twisted-tape inserts with the HLDTT condition were used, the heat transfer coefficients were $9-47 \%$ higher than those of the plain tubes.

3.3. Friction Factor. The variation of the pressure drop is presented in terms of the friction factor as shown in Figure 6. It shows the friction factor versus the Reynolds numbers for different combinations of inserts.

It is seen that the friction factors obtained from three different inserts follow a similar trend and this decreases with an increase in the Reynolds number. The increase in friction factor with swirl flow is much higher than that with an axial flow.

It was found that the pressure drop for the FLTT inserts was $203-623 \%$ higher than that for the plain tubes. For the HLUTT inserts, it was $36-170 \%$ higher than that for the plain tubes. However, the pressure drop for the HLUTT was 82$168 \%$ less than that for the FLLT inserts. For the HLDTT inserts, it was $31-144 \%$ higher than that for the plain tubes. It was seen that the highest pressure drop occurred when the tape inserts with a twist ratio $\lambda=0.38$ were used. 


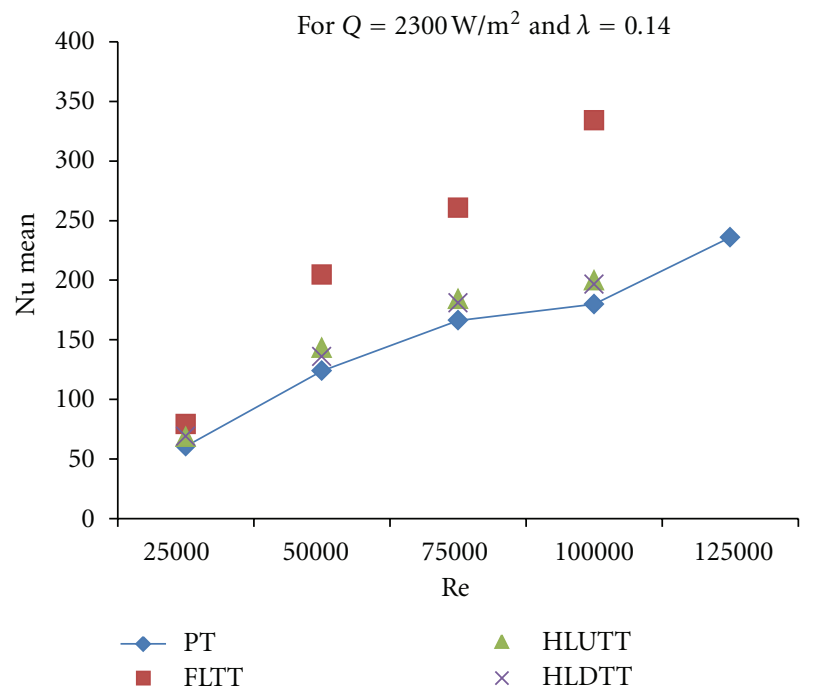

(a)

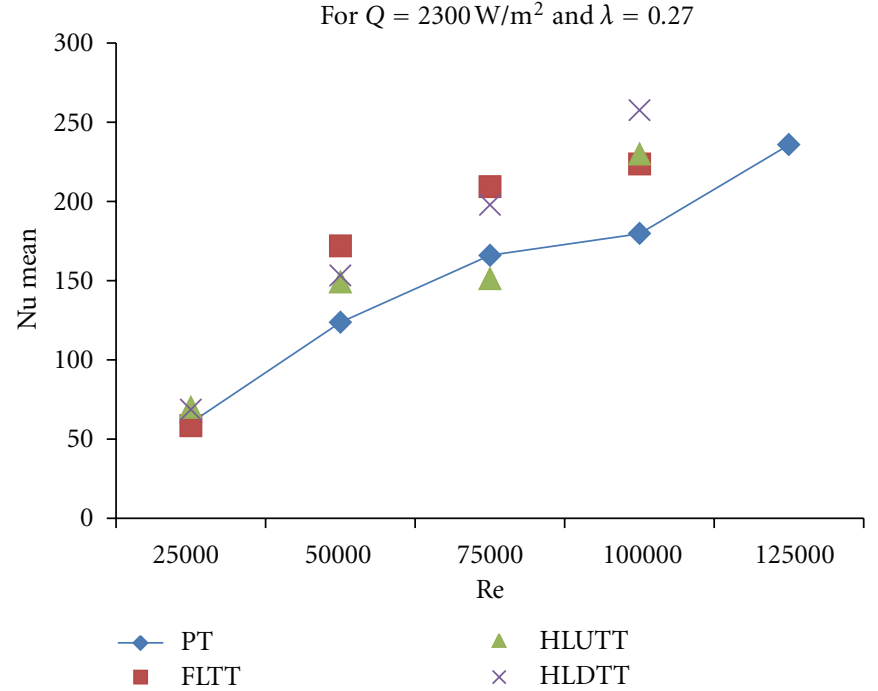

(b)

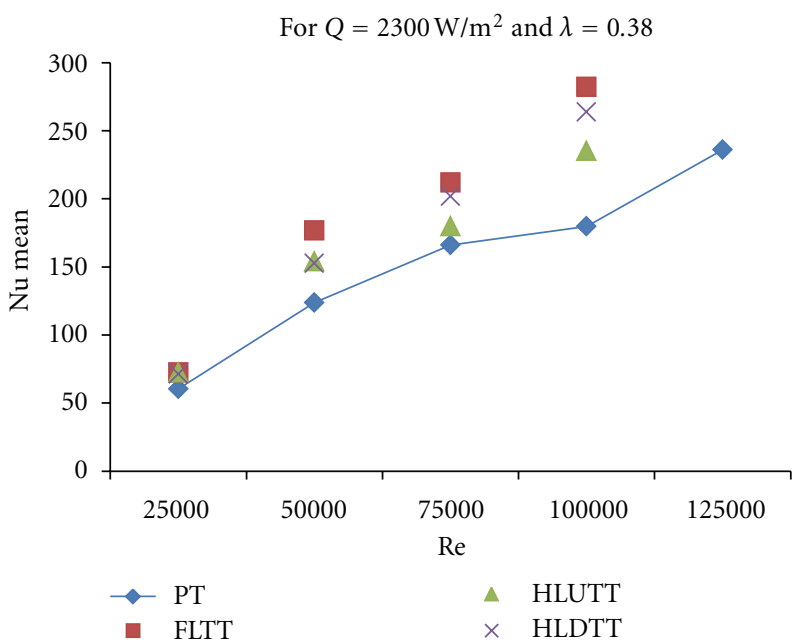

(c)

Figure 5: Variation of Nussle number (Nu) versus Re for different inserts: (a) for $\lambda=0.14$, (b) for $\lambda=0.27$ and, (c) for $\lambda=0.38$.

3.4. Thermal Performance Factor. From Figure 7, it has been observed that the thermal performance factor tends to decrease with an increasing twist parameter and with an increase in the Reynolds number for HLUTT and HLDTT twisted-tapes. Whereas for FLTT, it was found that thermal performance factor tends to decrease with an increasing twist ratio and increase with an increase in the Reynolds number. For all the twist ratios, the HLUTT and HLDTT configurations have been seen to give the thermal performance factors in the range of 1.02-1.16, which is comparable with those provided by the FLTT (1.03-1.24).

3.5. Streamline and Pathline. Plots of pathlines through the tube with twisted-tape inserts have been shown in Figure 8 . It is evident that the insertion of the tape induces the swirling flow, and the twisted-tapes generate two types of flows which are (1) a swirling flow and (2) an axial or straight flow near the tube wall. It is noteworthy that the
FLTT gives higher velocity of the fluid flow through the test section compared to those with partially extending tapes where decaying of swirl flow along the length of tube takes place.

3.6. Velocity Vector Plots. Vector plots of velocity predicted for the tubes with FLTT and PT configuration are depicted in Figure 9 and Figure 10. As seen in the figures, two longitudinal vortices are generated around tapes in the core flow area. These longitudinal vortices play a critical role of disturbing the boundary layer and making the temperature uniform in the core flow. And at the same time, it has been found that a vortex tends to decay along the length in case of HLUTT and HLDTT cases which are partially decaying due to absence of twisted-tape in the latter part of the test section as shown in Figure 11. Whereas for the HLUDTT case a vortex tends to grow along the length after the initial half part of the test section as shown in Figure 12. The tangential 


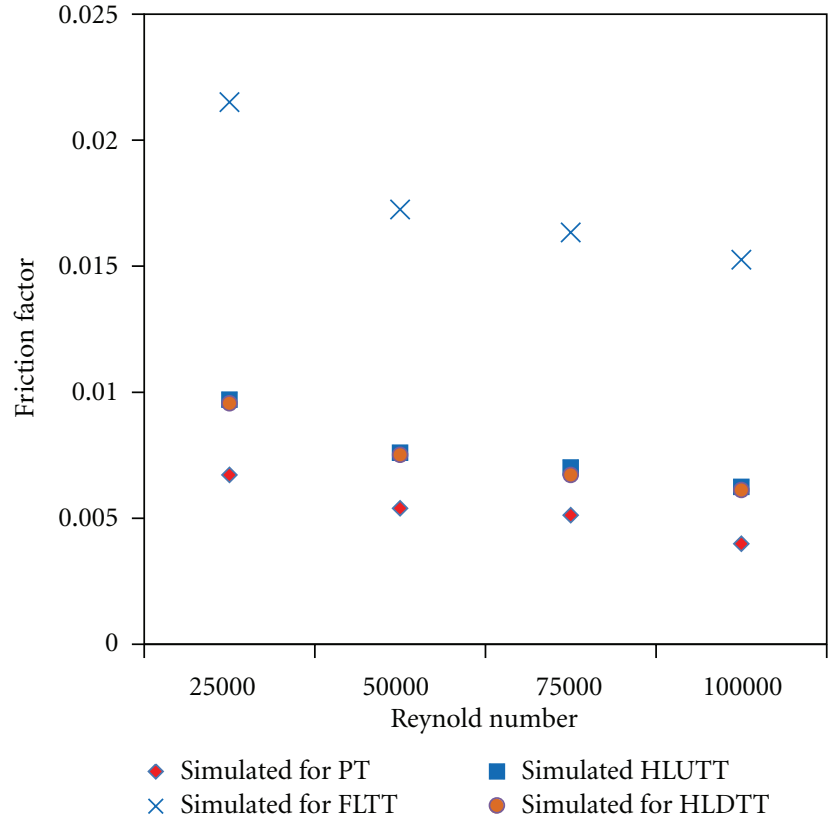

FIGURE 6: Variation of friction factor versus Re for different inserts for $\lambda=0.14$ at $Q=2300 \mathrm{~W} / \mathrm{m}^{2}$.

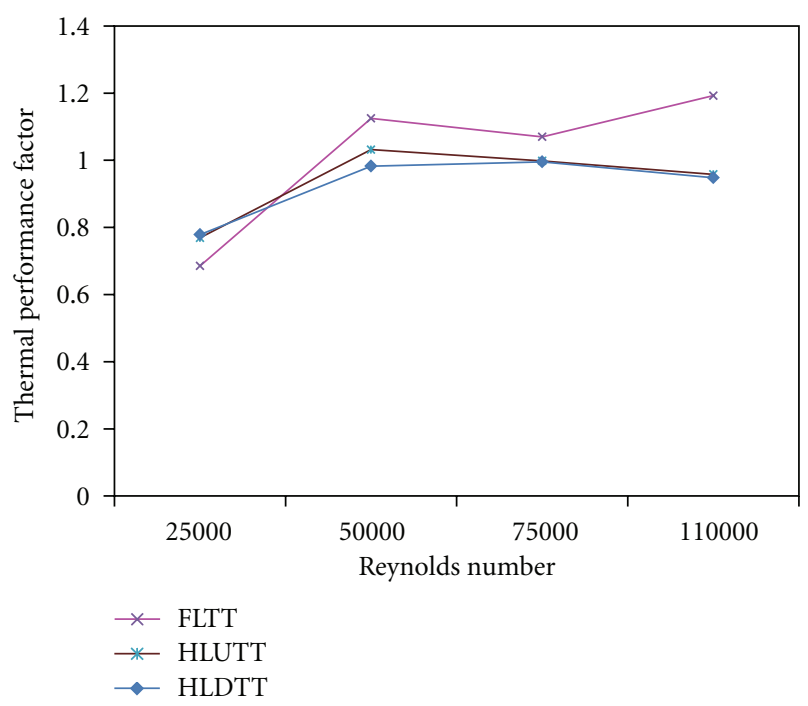

FIGURE 7: Variation of thermal performance factor versus Re for different inserts for $\lambda=0.14$ at $Q=2300 \mathrm{~W} / \mathrm{m}^{2}$.

velocity is almost zero for the plain tube at all the Reynolds numbers. However, it is seen that this velocity component increases when any of the above mentioned inserts are placed inside the tube.

\subsection{Temperature Profiles Analysis}

(a) Plain Tube Data. It is observed from the smooth tube temperature profile that the maximum wall temperature in the test section, $T_{\mathrm{wx}, \max }$, and the maximum temperature difference between the tube wall and the fluid, $\left(T_{\mathrm{wx}}-T_{\mathrm{bx}}\right)_{\max }$,

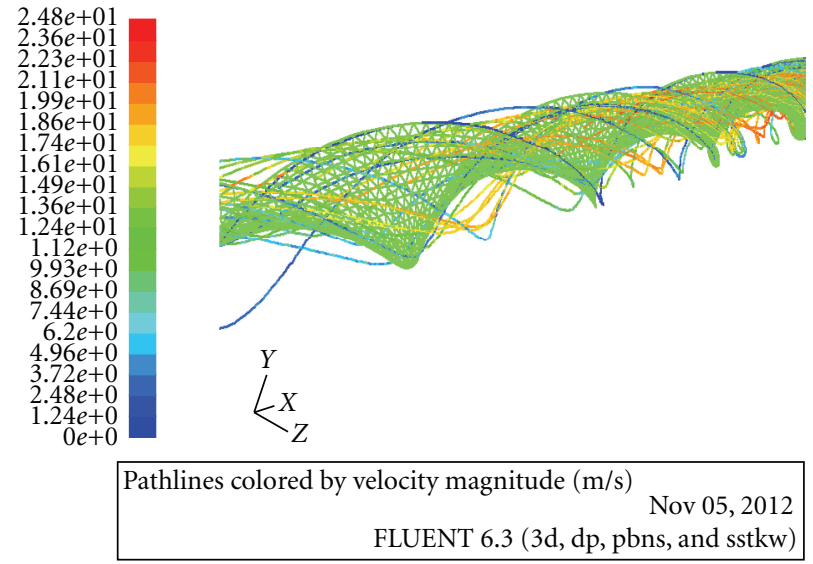

(a)

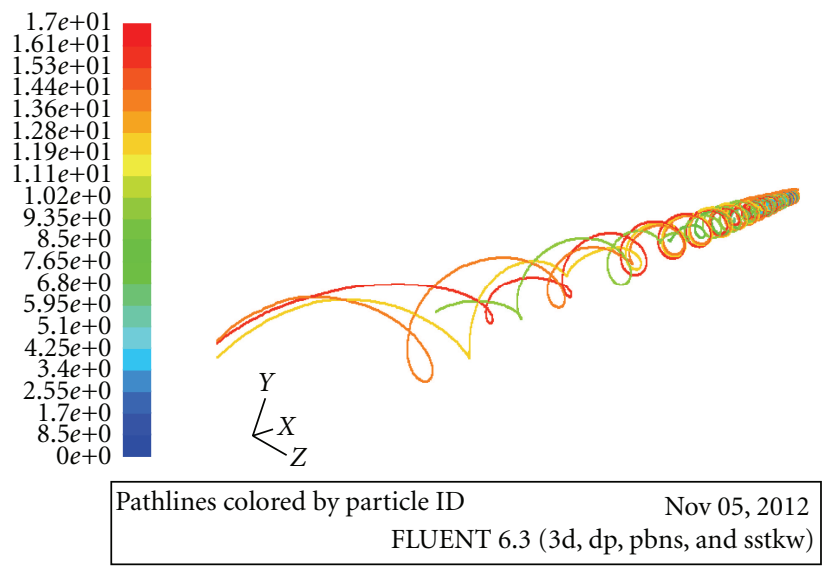

(b)

Figure 8: (a) Pathline through twisted-tape; (b) particle track through the tube with twisted-tape inserts.

both occur at $X / D=86 . T_{\mathrm{wx}, \max }$ varies from $48^{\circ} \mathrm{C}$ to $215^{\circ} \mathrm{C},\left(T_{\mathrm{wx}}-T_{\mathrm{bx}}\right)_{\max }$ varies from $10^{\circ} \mathrm{C}$ to $56^{\circ} \mathrm{C}$, and the wall temperature profile shows fully developed characteristics at roughly 17 diameters from entrance. At any location wall temperature decreases with Reynolds number and increases with heat flux.

(b) Twisted-Tape Data. Figures 13 and 14 show wall temperature profiles, for all the cases investigated. The data presented reveal the following trend.

(i) Effect of Reynolds Number on $T_{\mathrm{wx}}$. At any axial location the local wall temperature decreases with increasing Reynolds number. This is quite expected since heat transfer coefficients increase with Reynolds number bringing down both the wall to fluid temperature difference and the absolute wall temperature.

(ii) Effect of Heat Flux on $T_{\mathrm{wx}}$. In all the cases, an increase in heat flux results in an increase in the local wall temperature. For the upstream condition at $\lambda=0.14$, an increase in heat flux caused, in addition to an increase 

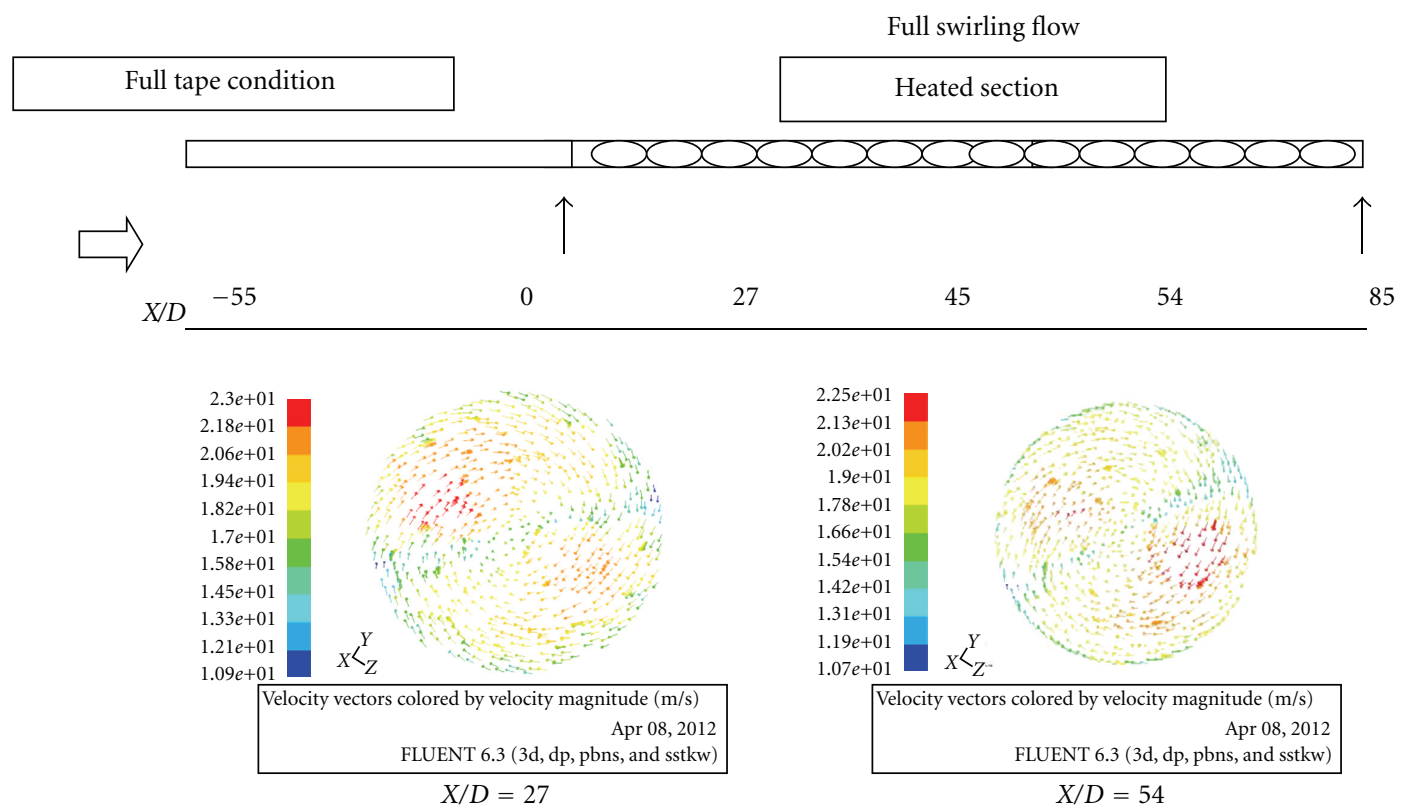

FIgURE 9: Vector plots across tube cross section along the axial length for FLTT with $\lambda=0.14, \operatorname{Re}=25000$, and $q=2300 \mathrm{~W} / \mathrm{m}^{2}$.

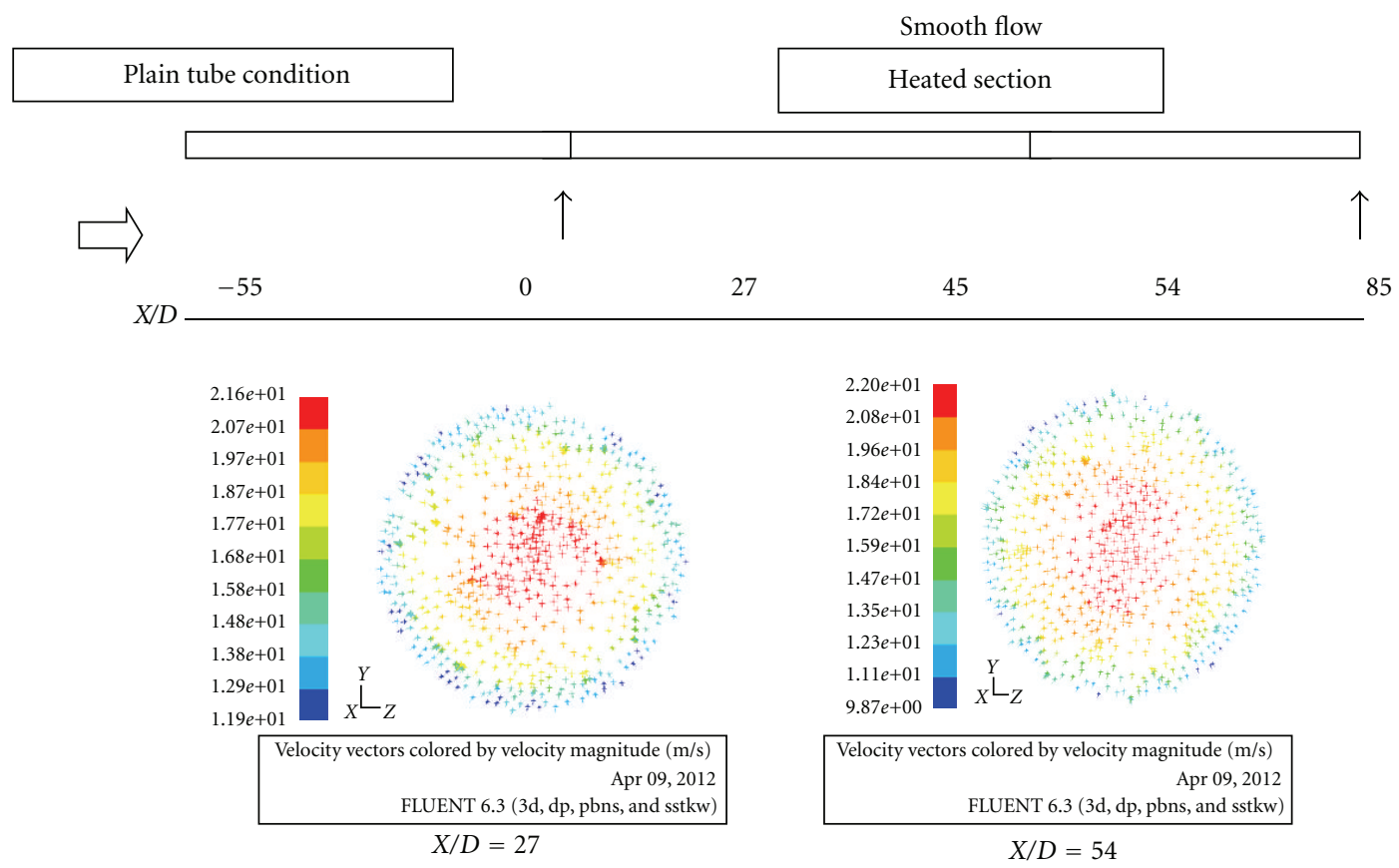

FIGURE 10: Vector plots across tube cross section along the axial length for PT with $\lambda=0.14, \operatorname{Re}=25000$, and $q=2300 \mathrm{~W} / \mathrm{m}^{2}$.

in the local wall temperature, a shift in the location of $\left(T_{\mathrm{wx}}-T_{\mathrm{bx}}\right)_{\min }$ from $X / D=36$ to $X / D=45$.

(iii) Effect of Twist Parameter on $T_{\mathrm{wx}}$. It is observed that the twist parameter $\lambda$ has a significant effect on both the magnitude of $T_{\mathrm{wx}}$ and its variation along the test section. Effect of $\lambda$ on $T_{\mathrm{wx}}$ will be discussed separately for the upstream and downstream conditions.
Upstream Condition. A dip in wall temperature is observed at the end of tape section for all values of $\lambda$. In the swirl decay section following the tape, the local wall temperature increases with an increase in $\lambda$.

Downstream Condition. The maximum wall temperature, $T_{\mathrm{wx}, \max }$ is located at $X / D=86$, for all values of $\lambda$. A steep temperature drop is noticed rear the entrance to tape section, 


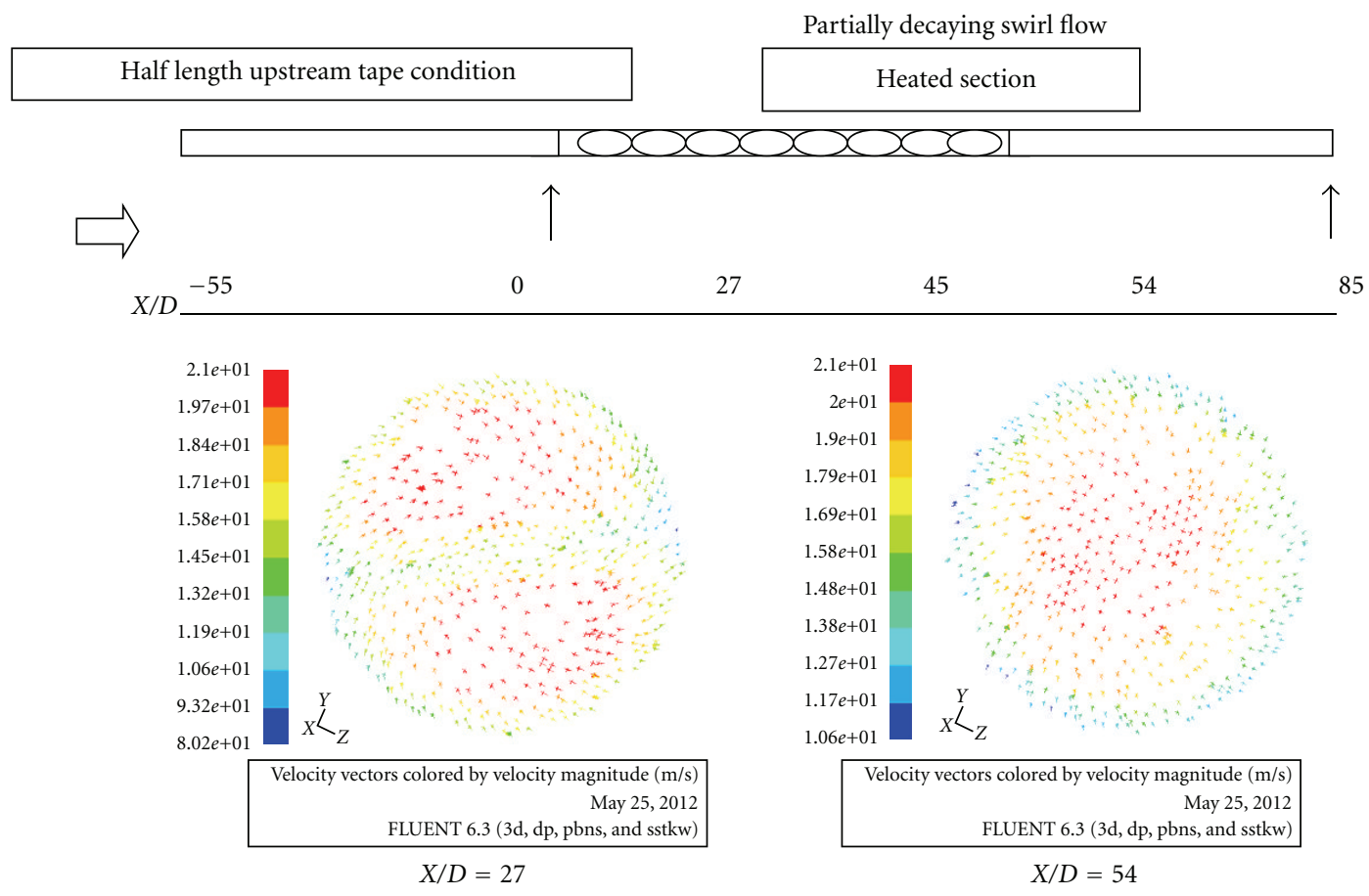

FIGURE 11: Vector plots across tube cross section along the axial length for HLUTT with $\lambda=0.14, \operatorname{Re}=25000$, and $q=2300 \mathrm{~W} / \mathrm{m}^{2}$.
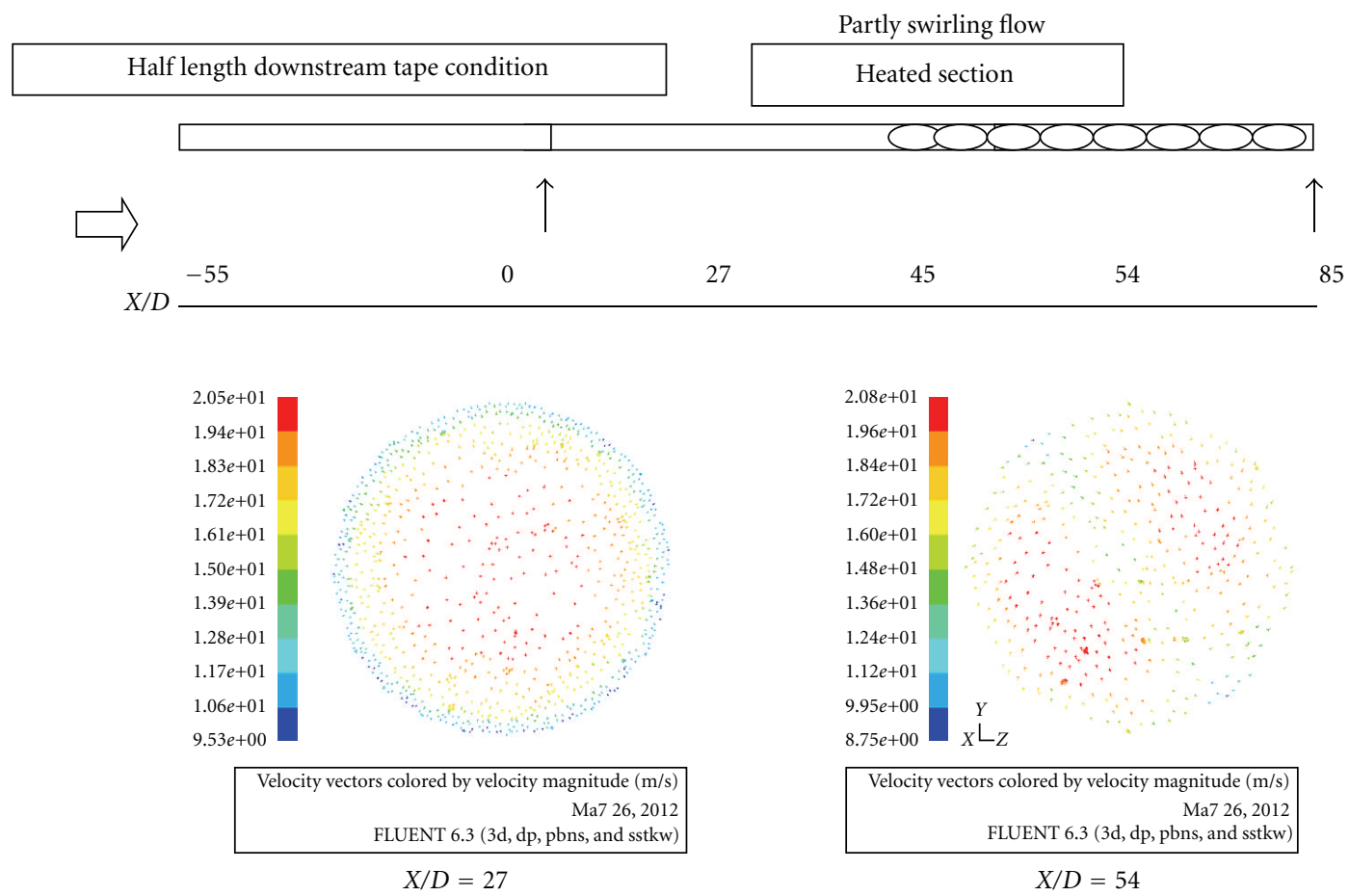

Figure 12: Vector plots across tube cross section along the axial length for HLDTT with $\lambda=0.14, \operatorname{Re}=25000$, and $q=2300 \mathrm{~W} / \mathrm{m}^{2}$. 


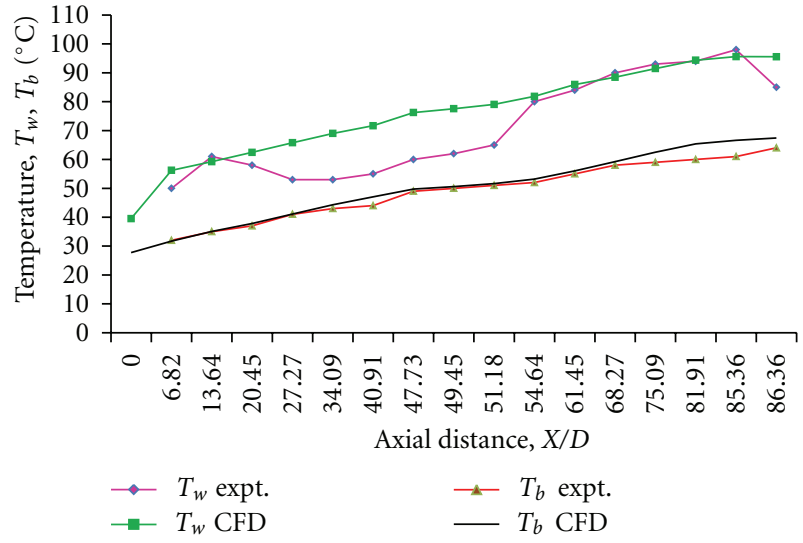

Figure 13: Experimental and CFD wall temp and surface temp for upstream location for $q=2300 \mathrm{~W} / \mathrm{m}^{2}, \operatorname{Re}=25000$, and $\lambda=0.14$.

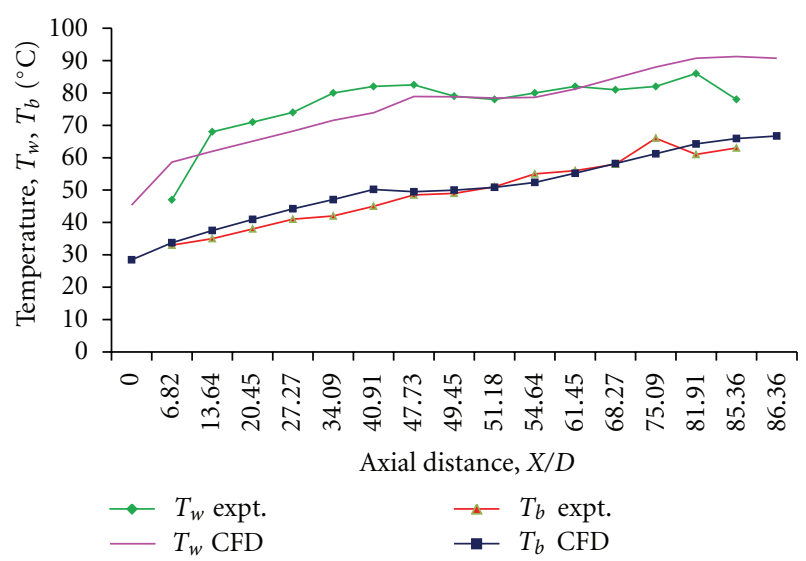

Figure 14: Expt. and CFD wall temp and surface temp for Downstream location for $q=2300 \mathrm{~W} / \mathrm{m}^{2}, \mathrm{Re}=25000$, and $\lambda=$ 0.14 .

for $\lambda=0.38$ and 0.27 , except for $\lambda=0.14$. For all values of $\lambda$, the tape section records the lowest wall temperature and the smooth section, the highest.

(iv) Effect of Tape Location on $T_{\mathrm{wx}}$. It is observed that the local wall temperatures are least for downstream condition. The effect of tape location on the maximum test section temperature, $T_{\mathrm{wx}, \max }$, is given below. Values are given as a percentage decrease from corresponding smooth tube values. See Table 2.

It is seen that downstream location of tape is most effective in bringing down the maximum test section wall temperature.

3.8. Local Nusselt Number Analysis. An examination of the local Nusselt number profiles for the upstream and downstream conditions as shown in Figure 15 shows that the Nusselt number attains local peaks, a characteristic which was noticed by Klepper [29] also in his experiments on partially extending tapes. This unusual behavior of the local Nusselt number has not been reported by any other
TABle 2: The effect of tape location on the maximum test section temperature, Twx, max.

\begin{tabular}{lcc}
\hline Tape location & Min & Max \\
\hline HLDTT & $5.2 \%$ & $19 \%$ \\
HLUTT & $0.0 \%$ & $6 \%$ \\
\hline
\end{tabular}

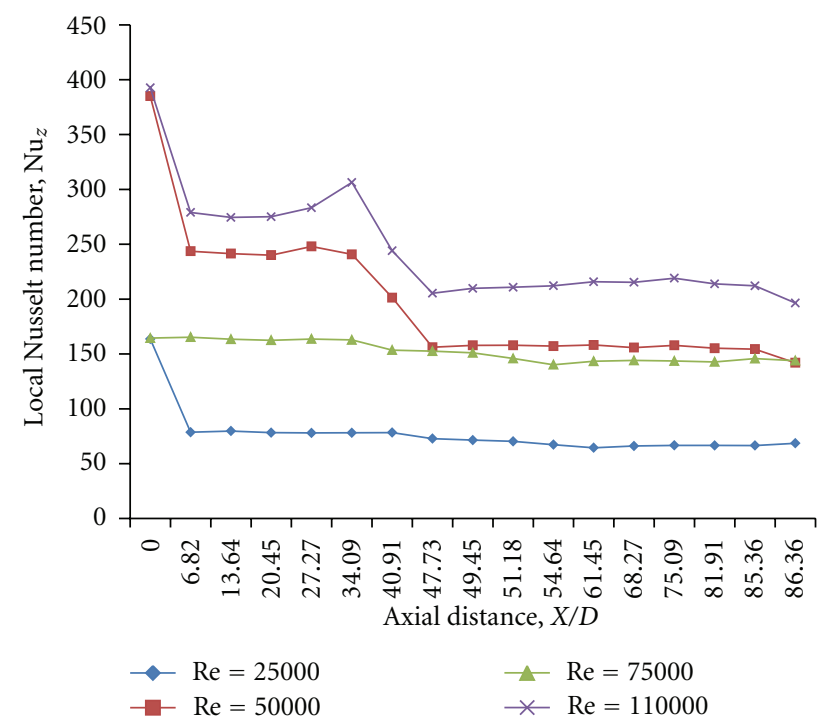

FIGURE 15: Local Nusselt number along axial distance for HLUTT for $\lambda=0.14, q=2300 \mathrm{~W} / \mathrm{m}^{2}$.

investigator. That the occurrence of these peaks is real and appears beyond doubt when it is observed that they occur at all Re, $\lambda$ and, $q$ and for both the downstream and upstream tape locations.

While, the characteristic of local peaks observed in the investigation can be used in avoiding the local hot spots in heat exchanger application, with possible application in such diverse areas as the cooling of an overheated rocket nozzle throat, prevention of burnout in space and earth power plants, and reduction of wall temperature in circulating fuel reactors and in the heat exchange equipment used in process industries. In most of the above applications temperatures critical to material life are likely to be reached, and as such any reduction in wall temperature would imply an improvement in performance.

\section{Conclusion}

The important issue in the present work can be expressed as the understanding of heat transfer and temperature analysis for fully, partially decaying, and partly swirl flow using the FLTT, HLUTT, and HLDTT twisted-tape insert.

The performance of this insert was compared with those of the FLTT twisted-tape inserts and the PT.

It was found that the heat transfer coefficient and the pressure drop in the tubes with the FLTT were 29-86\% and $203-623 \%$ greater than those in the case of the plain tubes without inserts. 
When the twisted-tape inserts with the HLUTT condition were used, the heat transfer coefficient and the pressure drop were estimated at $8-37 \%$ and $36-170 \%$ higher than those in the case of the plain tubes.

When the twisted-tape inserts with the HLDTT condition were used, the heat transfer coefficient and the pressure drop were estimated at $9-47 \%$ and $31-144 \%$ higher than those in the plain tube case.

It was found that thermal performance and local peak in heat transfer could be increased by using a combination of inserts with different geometries in the plain tubes while reducing the pressure drop. The characteristic of local peaks observed in the investigation can be used in avoiding the local hot spots in heat exchanger application.

Since the Nusselt number peaks were observed for both the downstream and upstream tape locations, the choice of tape location would be governed by the actual location of hot spots.

\section{Nomenclature}

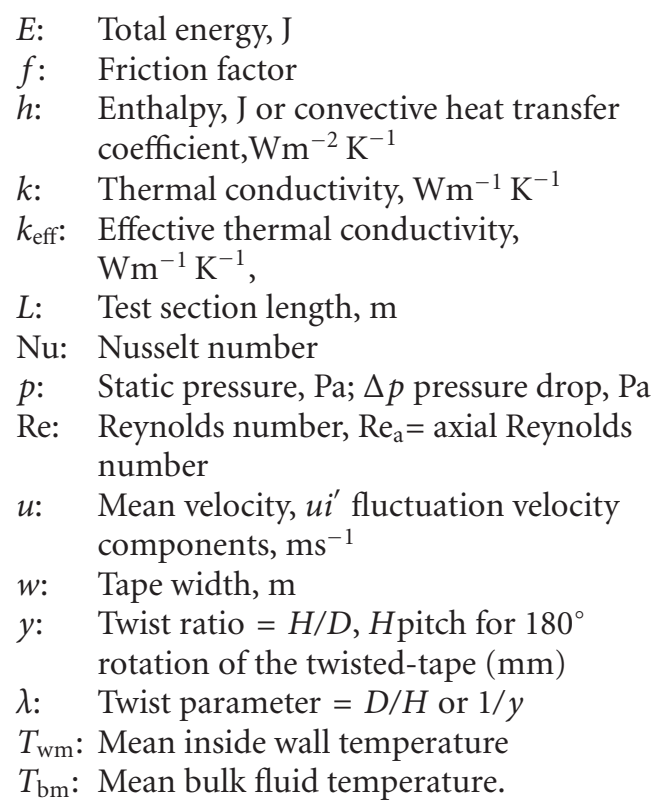

\section{Greek Symbols}

$\mu_{t}$ : Eddy viscosity, $\mathrm{kg} \mathrm{s}^{-1} \mathrm{~m}^{-1}$

$\eta$ : Thermal performance factor

$\delta$ : Thickness of the twisted-tape $(\mathrm{mm})$

$\varepsilon$ : Turbulent dissipation rate, $\mathrm{m}^{2} \mathrm{~s}^{-3}$.

\section{Acknowledgments}

The authors would like to acknowledge the keen interest taken by Late Dr. M.S. Lonath to start this research work. The moral support given to this investigation by Professor Dr. M.T. Karad is also appreciated and deeply recognized.

\section{References}

[1] A. E. Bergles, "Techniques to augment heat transfer," in Handbook of Heat Transfer Applications, J. P. Hartnett, W. M. Rohsenow, and E. N. Ganic, Eds., chapter 1, McGraw-Hill, New York, NY, USA, 2nd edition, 1985.

[2] R. L. Webb, Principle of Enhanced Heat Transfer, John Wiley, New York, NY, USA, 1994.

[3] A. R. A. Khaled, M. Siddique, N. I. Abdulhafiz, and A. Y. Boukhary, "Recent advances in heat transfer enhancements: a review report," International Journal of Chemical Engineering, vol. 2010, Article ID 106461, 28 pages, 2010.

[4] W. E. Hilding and C. H. Coogan, "Heat transfer and pressure loss measurements in internally finned tubes," in Proceedings of the ASME Symposium on Air Cooled Heat Exchangers, pp. 57-85, 1964.

[5] P. Bharadwaj, A. D. Khondge, and A. W. Date, "Heat transfer and pressure drop in a spirally grooved tube with twisted tape insert," International Journal of Heat and Mass Transfer, vol. 52, no. 7-8, pp. 1938-1944, 2009.

[6] M. A. Al-Nimr and M. K. Alkam, "Unsteady non-Darcian forced convection analysis in an annulus partially filled with a porous material," Journal of Heat Transfer, vol. 119, no. 4, pp. 799-804, 1997.

[7] Y. Ding, H. Alias, D. Wen, and R. A. Williams, "Heat transfer of aqueous suspensions of carbon nanotubes (CNT nanofluids)," International Journal of Heat and Mass Transfer, vol. 49, no. 12, pp. 240-250, 2006.

[8] K. Vafai and A. R. A. Khaled, "Analysis of flexible microchannel heat sink systems," International Journal of Heat and Mass Transfer, vol. 48, no. 9, pp. 1739-1746, 2005.

[9] A. R. A. Khaled and K. Vafai, "Analysis of thermally expandable flexible fluidic thin-film channels," Journal of Heat Transfer, vol. 129, no. 7, pp. 813-818, 2007.

[10] S. Tiwari, P. L. N. Prasad, and G. Biswas, "A numerical study of heat transfer in fin-tube heat exchangers using winglettype vortex generators in common-flow down configuration," Progress in Computational Fluid Dynamics, vol. 3, no. 1, pp. 32-41, 2003.

[11] E. M. Sparrow, J. E. Niethammer, and A. Chaboki, "Heat transfer and pressure drop characteristics of arrays of rectangular modules encountered in electronic equipment," International Journal of Heat and Mass Transfer, vol. 25, no. 7, pp. 961973, 1982.

[12] E. M. Sparrow, A. A. Yanezmoreno, and D. R. Otis Jr., "Convective heat transfer response to height differences in an array of block-like electronic components," International Journal of Heat and Mass Transfer, vol. 27, no. 3, pp. 469-473, 1984.

[13] Y. M. Chen and J. M. Ting, "Ultra high thermal conductivity polymer composites," Carbon, vol. 40, no. 3, pp. 359-362, 2002.

[14] S. Y. Kim, J. M. Koo, and A. V. Kuznetsov, "Effect of anisotropy in permeability and effective thermal conductivity on thermal performance of an aluminum foam heat sink," Numerical Heat Transfer; Part A, vol. 40, no. 1, pp. 21-36, 2001.

[15] D. A. Nield and A. V. Kuznetsov, "Forced convection in a helical pipe filled with a saturated porous medium," International Journal of Heat and Mass Transfer, vol. 47, no. 24, pp. 5175-5180, 2004.

[16] L. Cheng and A. V. Kuznetsov, "Heat transfer in a laminar flow in a helical pipe filled with a fluid saturated porous medium," International Journal of Thermal Sciences, vol. 44, no. 8, pp. 787-798, 2005. 
[17] L. Cheng and A. V. Kuznetsov, "Investigation of laminar flow in a helical pipe filled with a fluid saturated porous medium," European Journal of Mechanics, B/Fluids, vol. 24, no. 3, pp. 338-352, 2005.

[18] P. Promvonge and S. Eiamsa-ard, "Heat transfer enhancement in a tube with combined conical-nozzle inserts and swirl generator," Energy Conversion and Management, vol. 47, no. 18-19, pp. 2867-2882, 2006.

[19] P. Promvonge, "Heat transfer behaviors in round tube with conical ring inserts," Energy Conversion and Management, vol. 49, no. 1, pp. 8-15, 2008.

[20] E. Smithberg and F. Landis, "Friction and forced convection heat transfer characteristics in tubes with twisted tape swirl generators," Journal of Heat Transfer, vol. 86, no. 1, pp. 39-49, 1964.

[21] R. F. Lopina and A. E. Bergles, "Heat transfer and pressure drop in tape-generated swirl flow of single-phase water," Journal of Heat Transfer, vol. 91, pp. 434-442, 1968.

[22] A. W. Date, "Prediction of fully-developed flow in a tube containing a twisted-tape," International Journal of Heat and Mass Transfer, vol. 17, no. 8, pp. 845-859, 1974.

[23] R. M. Manglik and A. E. Bergles, "Heat transfer and pressure drop correlations for twisted-tape inserts in isothermal tubes: part I-laminar flows," Journal of Heat Transfer, vol. 115, no. 4, pp. 881-889, 1993.

[24] S. Al-Fahed, L. M. Chamra, and W. Chakroun, "Pressure drop and heat transfer comparison for both microfin tube and twisted-tape inserts in laminar flow," Experimental Thermal and Fluid Science, vol. 18, no. 4, pp. 323-333, 1998.

[25] S. K. Saha and A. Dutta, "Thermohydraulic study of laminar swirl flow through a circular tube fitted with twisted tapes," Journal of Heat Transfer, vol. 123, no. 3, pp. 417-427, 2001.

[26] M. Rahimi, S. R. Shabanian, and A. A. Alsairafi, "Experimental and CFD studies on heat transfer and friction factor characteristics of a tube equipped with modified twisted tape inserts," Chemical Engineering and Processing, vol. 48, no. 3, pp. 762770, 2009.

[27] S. Eiamsa-ard, C. Thianpong, P. Eiamsa-ard, and P. Promvonge, "Convective heat transfer in a circular tube with short-length twisted tape insert," International Communications in Heat and Mass Transfer, vol. 36, no. 4, pp. 365-371, 2009.

[28] Y. W. Chiu and J. Y. Jang, "3D numerical and experimental analysis for thermal-hydraulic characteristics of air flow inside a circular tube with different tube inserts," Applied Thermal Engineering, vol. 29, no. 2-3, pp. 250-258, 2009.

[29] O. H. Klepper, Experimental tudy of Heat Transfer and pressure drop for gas flowing in tubes containing a short twisted tape [M.S. thesis], University of Tennessee, 1971. 

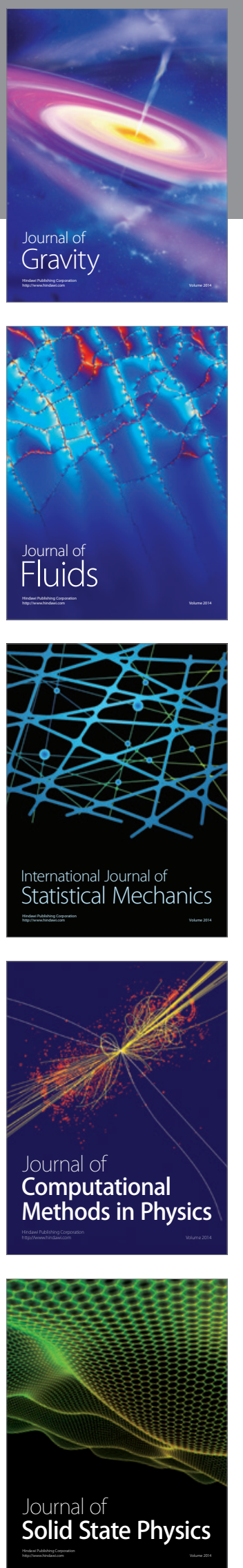

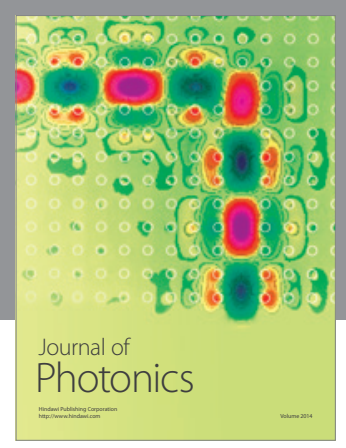

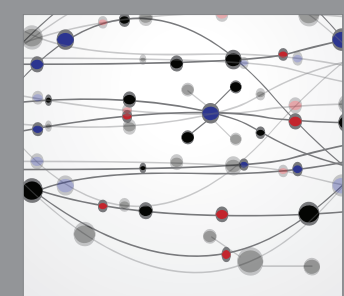

The Scientific World Journal
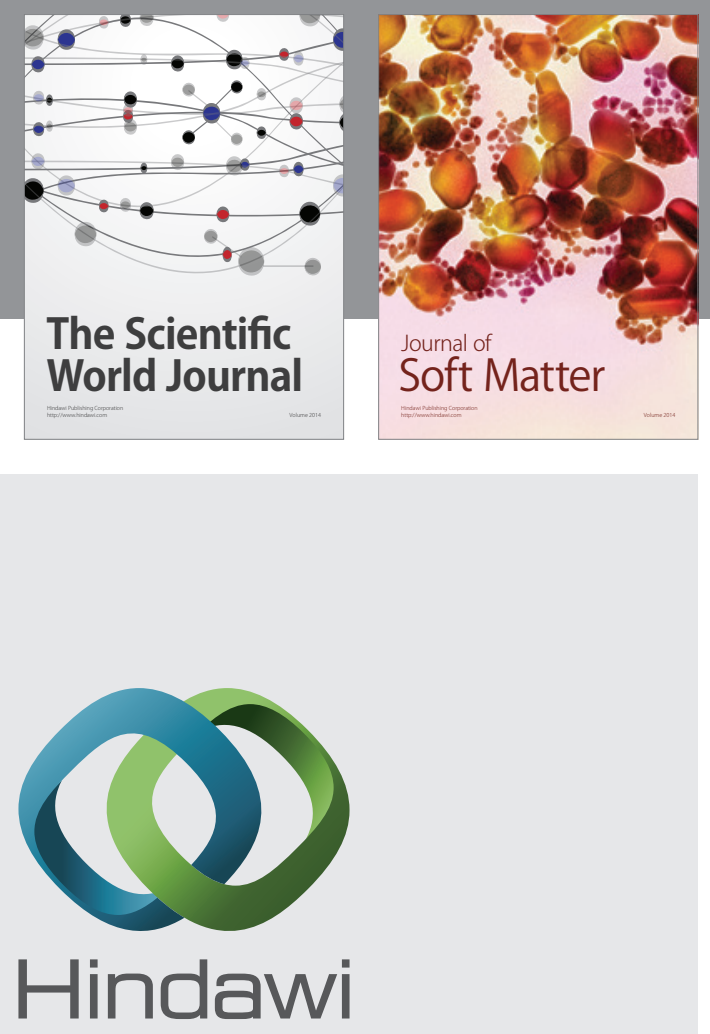

Submit your manuscripts at

http://www.hindawi.com
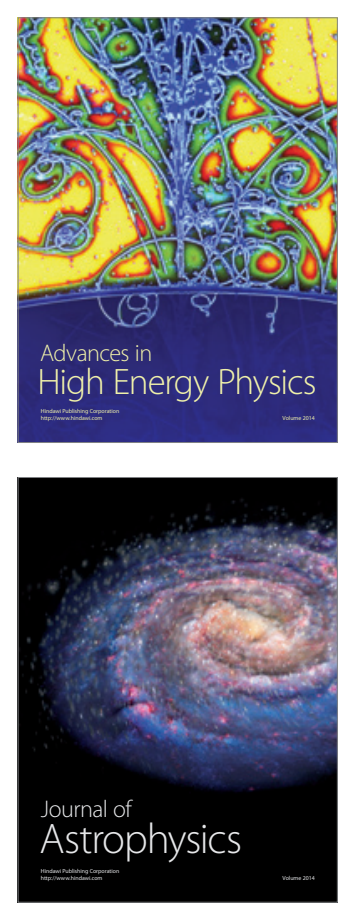
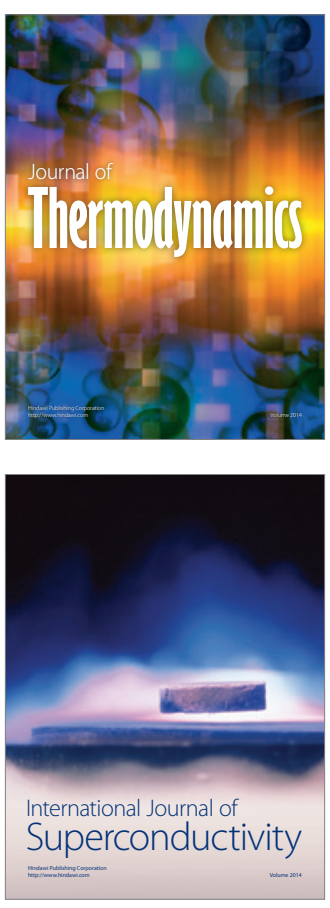
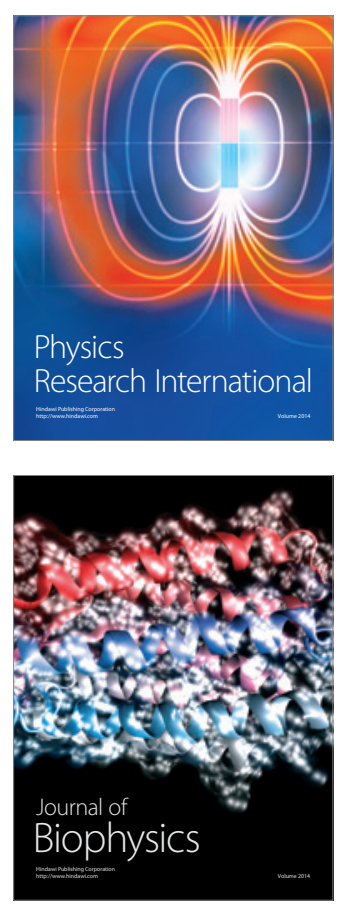
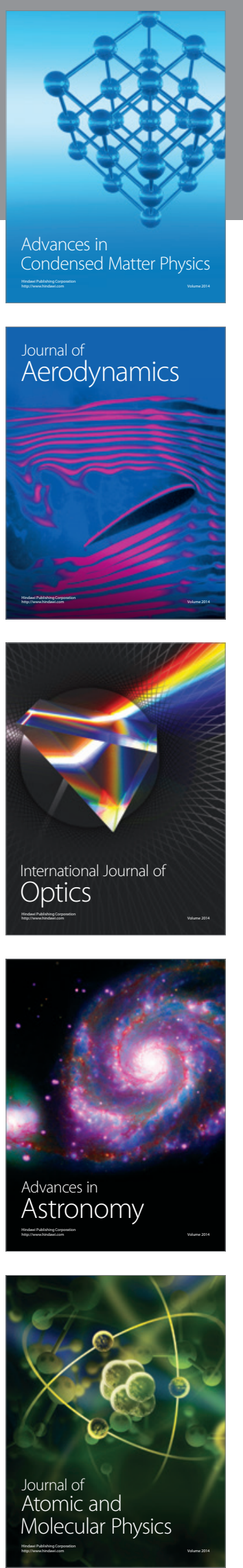